\title{
Neurological Symptoms in Palliative Care Patients
}

\author{
Johanna Anneser ${ }^{1 *}$, Victoria Arenz ${ }^{1}$ and Gian Domenico Borasio ${ }^{2}$ \\ ${ }^{1}$ Palliative Care Team, Department of Psychosomatic Medicine and Psychotherapy, Klinikum rechts der Isar, Technical \\ University Munich, Munich, Germany, ${ }^{2}$ Service de Soins palliatifs et de support, Centre Hospitalier Universitaire Vaudois \\ (CHUV), University of Lausanne, Lausanne, Switzerland
}

Background: Neurological expertise in palliative care may be required not only for patients with primary neurological disorders but also for patients with non-neurological diseases suffering from burdensome neurological symptoms. The aim of this study was to determine the prevalence of neurological diagnoses and symptoms in palliative care patients, as well as the related burden and impact on everyday life.

OPEN ACCESS

Edited by:

David John Oliver,

University of Kent,

United Kingdom

Reviewed by:

Teneille Emma Gofton,

University of Western

Ontario, Canada

Deepa Bhupali,

University of Illinois at

Chicago, United States

Idris Baker,

Abertawe Bro Morgannwg

University Health Board, United Kingdom

*Correspondence: Johanna Anneser j.anneser@tum.de

Specialty section:

This article was submitted

to Neurocritical and

Neurohospitalist Care,

a section of the journal

Frontiers in Neurology

Received: 07 February 2018

Accepted: 09 April 2018

Published: 25 April 2018

Citation:

Anneser J, Arenz V and Borasio GD (2018) Neurological Symptoms in

Palliative Care Patients.

Front. Neurol. 9:275.

doi: 10.3389/fneur.2018.00275
Methods: We analyzed retrospectively the medical records of 255 consecutive patients from a tertiary medical center, at the time point of referral to an inpatient palliative care consultation service. In addition, 100 patients prospectively answered a questionnaire which included the assessment of neurological symptoms, as well as numeric rating scales for quality of life, symptom-specific burden, and restrictions in everyday life.

Results: Forty-one patients (16\%) suffered from a primary neurological disease. Most decisions regarding the termination of life-sustaining measures concerned this group (20/22, 91\%). Neurological symptoms (excluding pain) were documented in 122 patients (48\%) with an underlying non-neurological disease. In the questionnaire study, 98/100 patients reported at least one neurological or neuropsychiatric symptom, most frequently sleeping problems ( $N=63)$, difficulty concentrating $(N=55)$, and sensory symptoms $(N=50)$. Vertigo/dizziness $(N=19)$ had the greatest impact on everyday life $(7.57 / 10 \pm 2.17)$ and the highest symptom-specific burden $(7.14 \pm 2.51)$. Difficulty concentrating (restrictions in everyday life/burden) and pain intensity were the only symptoms significantly correlated with quality of life $(r=-0.36, p=0.009 / r=-0.32 ; p=0.04$; $r=-0.327, p=0.003)$.

Conclusion: Neurological diseases and symptoms are frequent among palliative care patients and are often associated with a high symptom burden, which may severely affect the patients' lives. It is thus of paramount importance to implement neurological expertise in palliative care.

Keywords: palliative care, neurological symptoms, prevalence, symptom burden, quality of life

\section{INTRODUCTION}

Palliative care aims to provide physical, psychosocial, and spiritual care for terminally ill patients and their families. Although differences between countries exist, palliative care has been linked traditionally to oncological diseases and internal medicine/oncology specialists still constitute the largest part of the palliative care workforce in many countries (e.g., Germany, USA, Japan, and 
Canada) (1-4), while neurologists constitute less than $3 \%$ of physicians that are certified in palliative care $(1,2,4)$. On the other hand, neurological and neurosurgical diseases have been found to be the second most common conditions in patients seen by a palliative care inpatient consultation service (5) and the most common diagnostic group in patients with non-malignant diseases (6).

Several reviews advocate a better integration of palliative care in the overall care of patients with neurological diseases (7-9). Both neurological and palliative care expertise are required, e.g., for patients with intracranial processes in order to assess prognosis, to substantiate decisions on the withholding or withdrawal of life-sustaining measures and to help the family understand the nature of an imminent persistent vegetative state or brain death. Although care concepts for people with motor neuron diseases may be an encouraging example of the successful integration of palliative care and neurology, many patients with neurodegenerative, neuro-oncological as well as neurovascular diseases still have a wide range of unmet palliative care needs $(9,10)$.

In addition, neurological expertise is required for nonneurological palliative care patients suffering from neurological symptoms. Scarce data are available on the prevalence of neurological symptoms in a general palliative care population and most of the data have been assessed retrospectively. In a metaanalysis looking at symptom prevalence in a total of 25,000 patients with incurable cancer (11), "neurological symptoms" (without further specification) were documented in $15 \%$ of all patients and in $34 \%$ within their last 2 weeks of life. Even less is known about the relevance of neurological symptoms for the patients' lives (e.g., their subjective burden, the impact on patients' quality of life (QoL), or possible restrictions in the patients' everyday lives). We therefore combined a review of patient charts with a prospective questionnaire study in order to gain an overview of the frequency of neurological symptoms as well as their clinical relevance in a general palliative care population.

\section{MATERIALS AND METHODS}

\section{Retrospective Chart Analysis}

The charts of 255 consecutive patients who had been referred to the palliative care inpatient consultation service, were analyzed. Data were collected over a period of 9 months. Demographic data, diagnosis, reasons for current admission to the hospital, previous treatments as well as neurological and neuropsychiatric symptoms and preconditions-as listed in the patient charts prior to the referral to the palliative care team-were assessed.

\section{Prospective Questionnaire Study}

A total of 100 consecutive inpatients, referred to the palliative care inpatient consultation service, who were willing to participate and able to give their written informed consent were included in the questionnaire study. The questionnaire was administered in the form of a structured interview. The specific symptom burden is the degree to which the patients' everyday lives were compromised by a symptom and the patients' overall QoL were assessed using 0-10 point numeric rating scales (NRSs). NRS is a validated measure for QoL and is considered to assess the patient's general QoL rather than only its healthrelated aspects (12).

In order to differentiate lightheadedness or pre-syncopal syndromes from vertigo/dizziness, we asked the patients for the sensation of spinning/swaying and/or unsteady gait.

Actual pain intensity was assessed using a visual analog scale (VAS). To be able to compare the symptom "pain" with other neurological/neuropsychiatric symptoms, we assessed also the symptom-specific burden and restrictions in everyday life due to pain. Neuropathic pain was diagnosed by clinical assessment of the pain characteristics and the association with typical symptoms in the same area (e.g., tingling, numbness).

The "Confusion Assessment Method" (CAM) questionnaire was used when delirium was suspected. The CAM is a validated instrument for the diagnosis of delirium in a variety of medical settings $(13,14)$.

The Patient Health Questionnaire (PHQ-4) was used to screen patients for anxiety and depression.

In addition, patients were asked to name the symptoms, which were currently most distressing to them (max. 5). All patients who agreed received a structured neurological examination. Diagnostic workup of burdensome neurological symptoms was offered if indicated (e.g., neuro-otologic tests in patients with vertigo/dizziness). In addition, all patients were offered psychological support if desired. Descriptive statistics was performed using SPSS 24 (IBM, Chicago, IL, USA). Correlation analysis (Spearman's rho) was performed. The study was carried out in accordance with the recommendations of the Ethics Committee of the Technical University Munich. The protocol was approved by the Ethics Committee of the Technical University Munich (No: 5682/13). All subjects gave written informed consent in accordance with the Declaration of Helsinki.

\section{RESULTS}

\section{Analysis of Patient Charts Reasons for Admission to the Hospital as Documented in the Patient Chart}

Patients from nine different departments had been referred to the palliative care inpatient consultation service. For patient characteristics, see Table 1. In 84 out of 255 patients (33\%), the main reasons or one of the main reasons for admission to the hospital were neurological symptoms (other than pain). 28 patients $(11 \%)$ had been admitted directly to the departments of neurology or neurosurgery. The presence of neurological symptoms and preconditions-as documented in the admission examination or discovered in other examinations during the hospital stay-was assessed. Patients were assigned to one of four groups. (10 patients remained unclassified due to incomplete data or unclear assignment): 
TABLE 1 | Analysis of patients' medical records: patients' characteristics and neurological symptoms.

\begin{tabular}{lc}
\hline Patient characteristics & $\mathbf{2 5 5}$ patients \\
\hline Gender & $118(45 \%)$ female \\
Mean age & $67 \pm 13$ years \\
Mean duration of disease & $35 \pm 54$ months \\
Cancer diagnosis & $217(85 \%)$ \\
Primary brain tumor or cerebral metastases & $49(19 \%)$ \\
Previous surgery & $138(55 \%)$ \\
Previous chemotherapy & $157(63 \%)$ \\
Previous radiotherapy & $100(40 \%)$ \\
\hline
\end{tabular}

Neurological symptoms as documented in the patient chart

\begin{tabular}{|c|c|c|}
\hline Central paresis & 41 (16\%) & $\begin{array}{l}\text { Group 1: 25/41 (61\%) } \\
\text { Group 2: 12/99 (12\%) } \\
\text { Group 3: 4/23 (17\%) }\end{array}$ \\
\hline Seizures & 27 (11\%) & $\begin{array}{l}\text { Group 1: 22/41 (54\%) } \\
\text { Group 2: 14/99 (14\%) } \\
\text { Group 3: 1/23 (4\%) }\end{array}$ \\
\hline Dementia & 14 (6\%) & $\begin{array}{l}\text { Group 1: 10/41 (24\%) } \\
\text { Group 2: 0/99 (0\%) } \\
\text { Group 3: 4/23 (17\%) }\end{array}$ \\
\hline Confusion & 47 (19\%) & $\begin{array}{l}\text { Group 1: } 15 / 41(37 \%) \\
\text { Group 2: } 27 / 99(27 \%) \\
\text { Group 3: } 4 / 23(17 \%)\end{array}$ \\
\hline Other CNS symptoms & $66(26 \%)$ & $\begin{array}{l}\text { Group 1: 33/41 (80\%) } \\
\text { Group 2: 27/99 (27\%) } \\
\text { Group 3: 6/23 (26\%) }\end{array}$ \\
\hline Peripheral paresis & 27 (11\%) & $\begin{array}{l}\text { Group 1: } 3 / 41(7 \%) \\
\text { Group 2: } 20 / 99(20 \%) \\
\text { Group 3: 4/23 (17\%) }\end{array}$ \\
\hline Sensory symptoms & $23(9 \%)$ & $\begin{array}{l}\text { Group 1: 0/41 (0\%) } \\
\text { Group 2: 20/99 (20\%) } \\
\text { Group 3: } 3 / 23(13 \%)\end{array}$ \\
\hline
\end{tabular}

Group 1: primary neurological condition, group 2: neurological symptoms presumably caused by a non-neurological underlying disease, and group 3: neurological symptoms presumably independent from the underlying disease.

(1) A neurological condition is the primary underlying disease (e.g., stroke, neurodegenerative disorder, primary brain tumor): 41 patients $(16 \%)$

(2) Neurological symptoms (excluding pain) present and presumably caused by the (non-neurological) underlying disease and/or due to treatment of that disease: 99 patients (39\%)

(3) Neurological symptoms (excluding pain) present and presumably independent from the basic disease: 23 patients $(9 \%)$

(4) No neurological preconditions or symptoms documented: 82 patients $(32 \%)$

In most cases, no detailed neurological medical history had been assessed and no in-depth neurological examination had been performed before admission to the palliative care team. The most frequent neurological symptoms mentioned in the patient files are shown in Table 1. Neuropsychiatric symptoms such as sleeping problems, difficulty concentrating and impaired memory had not been assessed on a regular basis. "Taste abnormalities" were documented in none of the patient records.

\section{Termination of Life-Sustaining Measures}

After palliative care consultation, life-sustaining measures had been terminated in 22 patients, and 20 (91\%) of them had been classified in group I (neurological condition as primary disease).

\section{Patient Questionnaire Study Patient Characteristics}

For the questionnaire study, 100 of 255 consecutive patients who were willing to participate and able to give their informed consent were included (50\% female; 98 patients with cancer, 13 of them with brain metastases). 73 of 255 were not able to give their informed consent, 39 patients declined to participate, 32 patients could not be approached before the involvement of the palliative care consultation service, 11 lacked sufficient knowledge of the German language. None of the 41 neurologic patients could be recruited (20 were unconscious, 15 patients-mostly severe stroke or advanced glioblastoma-were conscious, but unable to consent, 5 refused to participate, and 1 lacked sufficient knowledge of the German language). 98 patients reported at least one neurological or neuropsychiatric symptom excluding pain, 38 patients stated that a neurologist or psychiatrist had treated them before admission to the hospital. Clinical neurological examination was performed after the patient interviews and objectified the symptoms reported (e.g., extent and degree of paresis or paresthesia). The values for "restrictions in everyday life" and "burden due to a specific symptom" were correlated, except for taste abnormalities.

\section{Prevalence of Neurological Symptoms}

The prevalence of neurological/neuropsychiatric symptoms, the symptom-specific burden, and restrictions in everyday life in patients participating in the questionnaire study is shown in Table 2. Sleeping problems (63/100), difficulties concentrating (55/100), and sensory symptoms (50/100) occurred most frequently. In addition, several neurological/neuropsychiatric symptoms were ranked among the most burdensome overall symptoms (Table 3 ).

\section{Neurological Symptoms and QoL}

The mean QoL $( \pm \mathrm{SD})$ (NRS 0-10) of all patients was $3.7( \pm 2.3)$. The only neurological non-pain symptom significantly correlated to QoL was difficulty concentrating (restrictions in everyday life: $r=-0.36, p=0.009$; symptom-specific burden: $r=-0.32$; $p=0.04$ ). In addition, the sum scores (restrictions in everyday life and symptom-specific burden) comprising the three most frequent neurological/neuropsychological symptoms (sleeping problems, difficulty concentrating and sensory symptoms) were significantly correlated with QoL $(r=-0.348, p=0.0004$; $r=-0.322, p=0.001$ ).

\section{Pain}

52 patients reported having only one pain localization, 27 patients reported having two, and 5 reported having three pain localizations. The most frequent type of pain was predominantly nociceptive (45 patients), followed by mixed pain (29 patients), and predominantly neuropathic pain (10 patients). Actual pain intensity - as measured by a VAS—correlated significantly with 
TABLE 2 | Prevalence of symptoms, restrictions in everyday life and burden due to specific symptoms (NRS 0-10).

\begin{tabular}{|c|c|c|c|}
\hline Neurological symptoms & $n=100$ & $\begin{array}{l}\text { Restrictions in } \\
\text { everyday life } \\
\text { Mean ( } \pm S D)\end{array}$ & $\begin{array}{c}\text { Burden due } \\
\text { to a specific } \\
\text { symptom } \\
\text { Mean }( \pm S D)\end{array}$ \\
\hline Pain & 84 & $6.52( \pm 3.04)$ & $6.48( \pm 3.08)$ \\
\hline $\begin{array}{l}\text { Sensory symptoms (numbness, } \\
\text { tightness, tingling, burning) }\end{array}$ & 50 & $4.67( \pm 3.27)$ & $4.21( \pm 3.34)$ \\
\hline Taste abnormalities & 32 & $3.62( \pm 2.79)$ & $5.62( \pm 2.83)$ \\
\hline Hearing impairment & 28 & $3.69( \pm 3.28)$ & $3.85( \pm 3.16)$ \\
\hline $\begin{array}{l}\text { Muscular symptoms other than } \\
\text { paresis (cramps, fasciculation) }\end{array}$ & 28 & NA & NA \\
\hline Vertigo/dizziness & 19 & $7.57( \pm 2.17)$ & $7.14( \pm 2.51)$ \\
\hline Paresis & 16 & $6.08( \pm 3.36)$ & $6.06( \pm 3.2)$ \\
\hline Coordination difficulties & 12 & $6.58( \pm 3.26)$ & $5.75( \pm 3.08)$ \\
\hline Double images & 10 & $6.00( \pm 3.2)$ & $5.90( \pm 3.38)$ \\
\hline Seizures & 6 & $4.75( \pm 4.43)$ & $5.00( \pm 4.08)$ \\
\hline Speech disorders & 4 & $4.00( \pm 3.65)$ & $6.50( \pm 3.11)$ \\
\hline \multicolumn{4}{|l|}{ Neuropsychiatric symptoms } \\
\hline Sleeping problems & 63 & $5.70( \pm 2.93)$ & $5.64( \pm 3.34)$ \\
\hline Difficulty concentrating & 55 & $3.85( \pm 3.18)$ & $4.44( \pm 3.12)$ \\
\hline Impaired memory & 44 & $3.36( \pm 3.21)$ & $4.29( \pm 3.11)$ \\
\hline \multicolumn{4}{|c|}{ Symptoms with possible neurological causes } \\
\hline Bladder or bowel disorder & 30 & $2.56( \pm 3.00)$ & $3.90( \pm 3.56)$ \\
\hline Dysarthria and/or dysphagia & 22 & $6.27( \pm 3.10)$ & $6.45( \pm 2.96)$ \\
\hline
\end{tabular}

TABLE 3 | Most distressing symptoms at the time of the interview named by 100 palliative care patients.

\begin{tabular}{ll}
\hline Frequency of mention & Symptoms \\
\hline $43 \times$ & General weakness, pain \\
$20 \times$ & Dyspnea \\
$13 \times$ & Nausea, fatigue, loss of appetite \\
$9 \times$ & Being worried/rumination \\
$5 \times$ & Paresis \\
$4 \times$ & Loss of autonomy, social isolation, bleeding, \\
& concentration problems, dysphagia \\
$3 \times$ & Sensory symptoms, vertigo/dizziness, diarrhea \\
$2 \times$ & Problems with stoma care, dysarthria, \\
& unsteady gait, anxiety, vision disturbances \\
& fever \\
$1 \times$ & Restlessness, cough, sleep disturbances, \\
& ascites, edema
\end{tabular}

Neurological and neuropsychiatric symptoms as assessed in the questionnaire study are printed in bold.

QoL ( $r=-0.327, p=0.003)$. Restrictions in everyday life and subjective burden due to pain did not correlate significantly with patients' QoL $(r=-0.135, p=0.21 ; r=-0.07, p=0.517)$.

\section{Depression and Anxiety (PHQ-4)}

Normal scores (0-2) were found in 28 patients, mild distress (3-5) in 28 patients, moderate (6-8) in 23 , and severe distress (9-12) in 21 patients. PHQ-4 showed a moderate correlation with QoL $(r=0.271, p=0.007)$. The PHQ-4 depression subscore was significantly correlated with the neuropsychological symptom "difficulty concentrating" $(r=0.361 p=0.003)$ and moderately, but significantly correlated with QoL $(r=-0.271$, $p=0.007)$.

\section{Delirium}

"Confusion" was documented in 47 patient charts (18.4\%), 12 were able to give their informed consent to study enrollment and underwent a screening test for delirium (CAM). The test-specific criteria for the diagnosis of "delirium" were fulfilled in 11 patients. No significant correlation with regard to age or gender was found in our study group.

\section{DISCUSSION}

Several studies investigated the presence of burdensome symptoms in patients with advanced cancer and palliative care patients [for a review, see Ref. $(11,15)]$. Isolated neurological symptoms such as agitation/delirium or vertigo/dizziness have been assessed in this context. However, a systematic and detailed analysis of neurological symptoms in palliative care patients has not been carried out before. We found that almost half of the palliative care patients without a primary neurological disease had neurological symptoms documented in their charts, and $98 \%$ of patients in the prospective study reported at least one burdensome neurological/ neuropsychological symptom. This is considerably higher than previously described (11). These findings have an immediate clinical relevance in that significant suffering arises from symptoms, which are underdiagnosed and therefore insufficiently treated. Our data suggest that this may be the case for a variety of neurological symptoms, which come with a high subjective burden and/or restrictions in everyday life, e.g., vertigo/dizziness, coordination difficulties, or double vision (Table 2).

\section{Sensory Symptoms}

The prevalence of sensory symptoms (numbness, tightness, tingling, and burning) reported in patients with advanced cancer and in palliative care patients varies widely from 6 to $36 \%$ (16-19). These variations may be caused by the different characteristics of the populations investigated, but also by the differing assessment methods used. Not surprisingly, it has been found that the prevalence of many symptoms is considerably lower when assessed using medical records as compared with studies using questionnaires or structured interviews (11). Correspondingly, the prevalence of sensory symptoms in our questionnaire study (50\%) was markedly higher than the results from the chart reviews (9\%).

\section{Dysgeusia}

Similar results were obtained for the prevalence of "taste abnormalities" (dysgeusia) in palliative care patients: in our study, the occurrence of dysgeusia in the patients' charts was $0 \%$, while $32 \%$ of patients in the questionnaire study reported taste abnormalities. Similarly, a previous interview study found that $86 \%$ of palliative care patients had taste abnormalities (20), while dysgeusia was documented in only $1-2 \%$ of patients' charts $(17,18)$.

\section{Dizziness/Vertigo}

Interestingly, our questionnaire study revealed "dizziness/vertigo" as the most burdensome symptom with the greatest impact on everyday life. "Vertigo"-defined as an erroneous sense of motion 
and unsteadiness-is a relatively common condition, which also occurs in the general population: a survey in Germany reported a 12 -month prevalence of $22.9 \%$ (21), while the point prevalence in palliative care patients with cancer was $10 \%$ (18). "Dizziness" is a term mostly used in a wider sense, which includes symptoms that range from a vague feeling of unsteadiness to severe vertigo. Pooled prevalence of dizziness in patients with incurable cancer was $17 \%$ in a previous study (11) and is similar to the occurrence found in our study (19\%). Our questionnaire allowed only an initial screening for dizziness/vertigo without providing an accurate diagnosis. A detailed analysis of dizziness/vertigo in palliative care patients is urgently warranted, since effective treatment is available for many forms of this symptom (22).

\section{Pain}

Pain had a prevalence of $84 \%$ in our palliative care population with a high symptom-specific burden and relevance for everyday life. Actual pain intensity correlated significantly with QoL, while symptom-related burden and restrictions in everyday life due to pain did not. An association between pain and QoL has been described previously, using the "brief pain inventory" $(23,24)$, but also an NRS $(25)$. In contrast to the VAS assessing actual pain intensity, our items asking for a "symptom-specific burden" or "restrictions in everyday life" implicate significant elements of personal judgment and/or coping and may therefore provide different results when correlated with QoL. 39\% of ourpredominantly oncologic-patients suffered from neuropathic pain. This matches the prevalence of neuropathic pain in cancer patients assessed in palliative care (43\%) and hospice settings (35\%) (26). A recent review revealed that neuropathic pain in cancer patients is often insufficiently treated because of "incorrect use of co-analgesics" (27).

\section{Delirium}

In $47(19 \%)$ patient charts from our cohort, "confusion" was documented. This percentage matches previous observations in a palliative care population (28). Since patients had to give informed consent to participate in the prospective study, only 12 patients underwent CAM testing in the context of our study, which was positive in 11 patients. Prevalence, diagnosis, treatment, and prognosis of confusion/delirium in palliative care patients have been widely studied (29). Recently, a randomized controlled trial showed that palliative care patients treated with standard neuroleptic medication had more delirium-specific symptoms, more side effects and a shorter survival rate than placebo-treated patients (30). This underscores the necessity of a careful diagnostic evaluation and individualized management of delirium in palliative care. Expertise in neuropharmacology and in the early detection of extra-pyramidal side effects of neuroleptic medication may be helpful to tailor treatment for these patients.

\section{Anxiety and Depression}

Anxiety and depression are common symptoms in palliative care patients (31) with an estimated prevalence ranging between 7 and 49\% (32). Correspondingly, 21\% of our patients scored 9-12/12 in the PHQ, indicating severe psychological distress.

\section{Sleeping Problems}

Similar to previous studies (33-35), sleeping problems were a frequent complaint among palliative care patients with a relatively high symptom-specific burden and impact on everyday activities. Sleep problems are multifactorial in many patients, although the moderate correlation with subjective burden due to pain suggests that inappropriate pain therapy may contribute to sleep disturbances in our patient population.

\section{Cognitive Symptoms}

A frequent occurrence of mild-to-moderate self-reported cognitive symptoms, such as difficulty concentrating or memory disturbances, has been described previously in palliative care and cancer patients $(16,17)$. In addition, in a previous study, cancer outpatients named "difficulty concentrating" as one of the 13 topranked symptoms (36). Correspondingly, difficulty concentrating was the only symptom (except pain) significantly correlated with QoL in our study. A previous report showed that complaints of difficulty concentrating did not correlate with objective measurements of cognitive function in palliative care patients (37). In our study group "difficulty concentrating" correlated significantly with the PHQ-4 depression subscore. It has been shown previously that the prevalence of depression in palliative care patients and patients with advanced cancer is greater than in the general population (38). Since difficulty concentrating is a complaint which is frequently associated with depression (39), this symptom may be part of a coexisting depressive syndrome. However, cognitive impairment and difficulty concentrating may also be accompanying symptoms of CNS processes or side effects of radiation therapy [for review, see Ref. (40)]. Expertise in organic forms of cognitive impairment may be helpful for the diagnostic classification of these symptoms in order to initiate appropriate treatment.

\section{Neurological/Neuropsychological Symptoms and QoL}

The significant correlations between the sum scores of the three most frequently reported neurological/neuropsychiatric symptoms (sleeping problems, difficulty concentrating, and sensory symptoms) and QoL, as well as the frequency at which neurological problems are reported to be one of the most distressing overall symptoms (Table 3), underscore the extent to which these symptoms may compromise the patients' well-being. Many neurological symptoms that turned out to be burdensome in the questionnaire study had not been assessed prior to the referral to the palliative care team. This underlines previous findings that physicians frequently tend to focus on their specialized scope of practice rather than giving sufficient attention to burdensome (e.g., neurological) symptoms in severely ill patients (41).

\section{Patients With Primary Neurological Diagnoses}

The percentage of patients with a primary neurological diagnosis (16\%) in our retrospective cohort is higher than the proportions found in previous studies $(9.2$ and $8.8 \%)(5,6)$; one of which however excluded patients with primary brain 
tumors (5). In our study, the overwhelming majority (91\%) of decisions regarding termination of life-sustaining measures (e.g., terminal extubation, termination of artificial hydration, and nutrition) were taken in patients with primary neurological diseases. This is in line with the findings of Liu et al. (6), who showed that "eliciting goals of care" was the most frequent reason for palliative care consultations among neurological patients. In-depth knowledge of the course and prognosis of neurological diseases is indispensable when discussing treatment options with the patients' families. Generally, there is an increasing awareness that many patients suffering from neurological diseases have palliative care needs $(7,8)$ and efforts have been made to improve the education of neurologists in this context (42).

\section{Neurological Expertise in Palliative Care}

Given the high prevalence and the considerable burden of neurological symptoms in palliative care patients, as well as the relatively high percentage of patients with primary neurological disorders, it becomes evident that neurological expertise is crucial in palliative care. It can be fostered by increased neurological training in postgraduate palliative care education, as well as by recruiting neurologists in specialized palliative care centers. However, relatively few neurologists choose to abandon their primary specialty to concentrate on palliative medicine full-time. Clinical rotations of neurologists in palliative care teams may not only help to integrate neurological knowledge into palliative care, but also open up career options for young neurologists (2).

\section{Limitations}

The single center design may limit the generalizability of the study. However, referral of patients from nine different departments of our university hospital resulted in a highly heterogeneous study population with a wide range of diagnoses. Our study was conducted in a tertiary medical center that has departments of neurology and neurosurgery. Therefore, the number of patients with primary neurological disorders may be higher than in less specialized hospitals. In the prospective cohort, $98 \%$ of patients suffered from cancer. The significance of the results from the questionnaire study may therefore apply primarily to oncological palliative care patients. Unfortunately, this also reflects the disproportionate prevalence of tumor patients in most specialized palliative care centers worldwide.

\section{REFERENCES}

1. German Society for Palliative Care. Member Structure (in German) (2011). Available from: http://www.dgpalliativmedizin.de/images/intern/mitgliedschaft/MItgliederstruktur_der_DGP_Mai_2011.pdf (Accessed: June 30, 2017).

2. Dallara A, Tolchin DW. Emerging subspecialties in neurology: palliative care. Neurology (2014) 82:640-2. doi:10.1212/WNL.0000000000000121

3. Morita T, Oyama Y, Cheng SY, Suh SY, Koh SJ, Kim HS, et al. Palliative care physicians' attitudes toward patient autonomy and a good death in east Asian countries. J Pain Symptom Manage (2015) 50(2):190-9.e1. doi:10.1016/j. jpainsymman.2015.02.020
Similar to other centers $(43,44)$ patients with non-malignant diseases including primary neurological disorders were referred to our palliative care consult service only at a very late stage. These patients were unable to consent and could not recruited for the prospective study. Similarly, patients of all disease stages and neurological symptoms that affected their ability to consent (e.g., delirium) were excluded from the study. Hence, the prevalence of neurologic symptoms in a general palliative care population may be even higher and the symptoms more burdensome than found in our prospective study group.

Finally, the NRSs for the assessment of symptom-specific burden and for restrictions in everyday life used in our study had not been validated previously. However, NRSs allow for a direct comparison between specific neurological symptoms and help reducing the study burden for the severely ill patients to a minimum.

\section{CONCLUSION}

A majority of palliative care patients in our study suffered from neurological symptoms in varying degrees, frequently causing considerable symptom burden and restrictions in everyday life. Some of these symptoms are not well documented in patient charts and may remain undiagnosed and untreated. In addition, the question of withdrawal of life-sustaining treatment is most frequently posed in patients with primary neurological diseases. In consequence, palliative care teams are confronted on a daily basis with complex neurological questions and burdensome neurologic symptoms. This underscores the importance of the neurological expertise in palliative care teams.

\section{AUTHOR CONTRIBUTIONS}

JA was involved in the conception and design of the study, the statistical analysis and interpretation of data, and drafted the manuscript. VA was involved in the design of the study, in the acquisition of data, and approved the final manuscript. GB was involved in the conception of the study, and critically reviewed, revised, and approved the manuscript.

\section{FUNDING}

The study has been supported by a grant no. H420 72189999 22190 from the "Stifterverband für die Deutsche Wissenschaft."

4. Canadian Society of Palliative Care Physicians Human Resources Committee. National Palliative Medicine Survey Data Report (2015). Available from: https://www.cma.ca/Assets/assets-library/document/en/advocacy/pmsurvey-data-report-may2015-e.pdf (Accessed: February 6, 2018).

5. Chahine LM, Malik B, Davis M. Palliative care needs of patients with neurologic or neurosurgical conditions. Eur J Neurol (2008) 15:1265-72. doi:10.1111/j.1468-1331.2008.02319.x

6. Liu Y, Kline D, Aerts S, Youngwerth JM, Kutner JS, Silau S, et al. Inpatient palliative care for neurological disorders: lessons from a large retrospective series. J Palliat Med (2017) 20:59-64. doi:10.1089/jpm.2016.0240

7. Borasio GD. The role of palliative care in patients with neurological diseases. Nature Rev Neurol (2013) 9:292-5. doi:10.1038/nrneurol.2013.49 
8. Boersma I, Miyasaki J, Kutner J, Kluger B. Palliative care and neurology. Time for a paradigm shift. Neurology (2014) 83:561-7. doi:10.1212/WNL. 0000000000000674

9. Provinciali L, Carlini G, Tarquini D, Defanti CA, Veronese S, Pucci E. Need for palliative care for neurological diseases. Neurol Sci (2016) 37: 1581-7. doi:10.1007/s10072-016-2614-x

10. Robinson MT, Holloway RG. Palliative care in neurology. Mayo Clin Proc (2017) 92(10):1592-601. doi:10.1016/j.mayocp.2017.08.003

11. Teunissen SC, Wesker W, Kruitwagen C, de Haes HC, Voest EE, de Graeff A. Symptom prevalence in patients with incurable cancer. A systematic review. J Pain Symptom Manage (2007) 34:94-104. doi:10.1016/j.jpainsymman. 2006.10.015

12. Chiò A, Gauthier A, Montuschi A, Calvo A, Di Vito N, Ghiglione P, et al. A cross sectional study on determinants of quality of life in ALS. J Neurol Neurosurg Psychiatry (2004) 75(11):1597-601. doi:10.1136/jnnp.2003.033100

13. Inouye S, van Dyck C, Alessi C, Balkin S, Siegal A, Horwitz R. Clarifying confusion: the confusion assessment method. Ann Intern Med (1990) 113(12):941-8. doi:10.7326/0003-4819-113-12-941

14. Shi Q, Warren L, Saposnik G, Macdermid JC. Confusion assessment method: a systematic review and meta-analysis of diagnostic accuracy. Neuropsychiatr Dis Treat (2013) 9:1359-70. doi:10.2147/NDT.S49520

15. Van Lancker A, Velghe A, Van Hecke A, Verbrugghe M, Van Den Noortgate $\mathrm{N}$, Grypdonck M, et al. Prevalence of symptoms in older cancer patients receiving palliative care: a systematic review and meta-analysis. J Pain Symptom Manage (2014) 47(1):90-104. doi:10.1016/j.jpainsymman.2013.02.016

16. Portenoy RK, Thaler HT, Kornblith AB, Lepore JM, Friedlander-Klar H, Coyle N, et al. Symptom prevalence, characteristics and distress in a cancer population. Qual Life Res (1994) 3:183-9. doi:10.1007/BF00435383

17. Srömgren AS, Groenvold M, Pedersen L, Olsen AK, Sjogren P. Symptomatology of cancer patients in palliative care: content validation of self-assessment questionnaires against medical records. Eur J Cancer (2002) 38:788-94. doi:10.1016/S0959-8049(01)00470-1

18. Potter J, Hami F, Bryan T, Quigley C. Symptoms in 400 patients referred to palliative care services: prevalence and patterns. Palliat Med (2003) 17:310-4. doi:10.1191/0269216303pm760oa

19. Zhou T, Yang K, Thapa S, Liu H, Wang B, Yu S. Differences in symptom burden among cancer patients with different stages of cachexia. J Pain Symptom Manage (2017) 53(5):919-26. doi:10.1016/j.jpainsymman.2016.12.325

20. Heckel M, Stiel S, Ostgathe C. Smell and taste in palliative care: a systematic analysis of literature. Europ Arch Otorhinolaryngol (2015) 272:279-88. doi:10.1007/s00405-014-3016-4

21. Neuhauser HK. Epidemiology of vertigo. Curr Opin Neurol (2007) 20:40-6. doi:10.1097/WCO.0b013e328013f432

22. Strupp M, Dieterich $M$, Brandt $T$. The treatment and natural course of peripheral and central vertigo. Dtsch Ärztebl Int (2013) 110:505-15. doi:10.3238/ arztebl.2013.0505

23. Park KU. Assessment of change of quality of life in terminally ill patients under cancer pain management using the EORTC Core Quality of Life Questionnaire (QLQ-C30) in a Korean sample. Oncology (2008) 74(Suppl 1): 7-12. doi:10.1159/000143212

24. Deng D, Fu L, Zhao YX, Wu X, Zhang G, Liang C, et al. The relationship between cancer pain and quality of life in patients newly admitted to Wuhan Hospice Center of China. Am J Hosp Palliat Care (2012) 29:53-9. doi:10.1177/1049909111418636

25. Mikan F, Wada M, Yamada M, Takahashi A, Onishi H, Ishida M, et al. The association between pain and quality of life for patients with cancer in an outpatient clinic, an inpatient oncology ward, and inpatient palliative care units. Am J Hosp Palliat Care (2016) 33:782-90. doi:10.1177/1049909116630266

26. Roberto A, Deandrea S, Greco MT, Corli O, Negri E, Pizzuto M, et al. Prevalence of neuropathic pain in cancer patients: pooled estimates from a systematic review of published literature and results from a survey conducted in 50 Italian palliative care centers. J Pain Symptom Manage (2016) 51:1091-102. doi:10.1016/j.jpainsymman.2015.12.336

27. Haumann J, Joosten EBA, Everdingen MHJVDB. Pain prevalence in cancer patients: status quo or opportunities for improvement? Curr Opin Suppirt Palliat Care (2017) 11:99-104. doi:10.1097/SPC.0000000000000261

28. Barnes J, Kite S, Kumar M. The recognition and documentation of delirium in hospital palliative care inpatients. Palliat Supp Care (2010) 8:133-6. doi:10.1017/S1478951509990873
29. Leonard MM, Agar M, Spiller JA, Davis B, Mohamad MM, Meagher DJ, et al. Delirium diagnostic and classification challenges in palliative care: subsyndromal delirium, comorbid delirium-dementia, and psychomotor subtypes. J Pain Symptom Manage (2014) 48:199-214. doi:10.1016/j. jpainsymman.2014.03.012

30. Agar MR, Lawlor PG, Quinn S, Draper B, Caplan GA, Rowett D, et al. Efficacy of oral risperidone, haloperidol, or placebo for symptoms of delirium among patients in palliative care: a randomized clinical trial. JAMA Intern Med (2017) 177:34-42. doi:10.1001/jamainternmed.2016.7491

31. Teunissen SC, de Graeff A, Voest EE, de Haes JC. Are anxiety and depressed mood related to physical symptom burden? A study in hospitalized advanced cancer patients. Palliat Med (2007) 21:341-6. doi:10.1177/0269216307079067

32. Walker J, Holm Hansen C, Martin P, Sawhney A, Thekkumpurath P, Beale C, et al. Prevalence of depression in adults with cancer: a systematic review. Ann Oncol (2013) 24:895-900. doi:10.1093/annonc/mds575

33. Conill C, Verger E, Henríquez I, Saiz N, Espier M, Lugo F, et al. Symptom prevalence in the last week of life. J Pain Symptom Manage (1997) 14:328-31. doi:10.1016/S0885-3924(97)00263-7

34. Mercadante S, Aielli F, Adile C, Ferrara P, Valle A, Cartoni C, et al. Sleep disturbances in patients with advanced cancer in different palliative care settings. J Pain Symptom Manage (2015) 50:786-92. doi:10.1016/j.jpainsymman. 2015.06.018

35. Mercadante S, Adile C, Ferrera P, Masedu F, Valenti M, Aielli F. Sleep disturbances in advanced cancer patients admitted to a supportive/palliative care unit. Support Care Cancer (2017) 25:1301-6. doi:10.1007/s00520-016-3524-4

36. Williams AR, Mowlazadeh B, Sisler L, Williams PD. Self-reported assessment of symptoms and self-care within a cohort of U.S. veterans during outpatient care for cancer. Clin J Oncol Nurs (2015) 19:595-602. doi:10.1188/15. CJON.595-602

37. Klepstad P, Hilton P, Moen J, Fougner B, Borchgrevink PC, Kaasa S. Selfreports are not related to objective assessments of cognitive function and sedation in patients with cancer pain admitted to a palliative care unit. Palliat Med (2002) 16:513-9. doi:10.1191/0269216302pm587oa

38. Mitchell AJ, Chan M, Bhatti H, Halton M, Grassi L, Johansen C, et al. Prevalence of depression, anxiety, and adjustment disorder in oncological, haematological, and palliative-care settings: a meta-analysis of 94 interview-based studies. Lancet Oncol (2011) 12(2):160-74. doi:10.1016/S14702045(11)70002-X

39. Papakostas GI, Culpepper L. Understanding and managing cognition in the depressed patient. JClin Psychiatry (2015) 76(4):418-25. doi:10.4088/ JCP.13086ahlc

40. Armstrong CL, Gyato K, Awadalla AW, Lustig R, Tochner ZA. A critical review of the clinical effects of therapeutic irradiation damage to the brain: the roots of controversy. Neuropsychol Rev (2004) 14:65-86. doi:10.1023/B: NERV.0000026649.68781.8e

41. Bainbridge D, Seow H, Sussman J, Pond G, Martelli-Reid L, Herbert C, et al. Multidisciplinary health care professionals' perceptions of the use and utility of a symptom assessment system for oncology patients. J Oncol Pract (2011) 7(1):19-23. doi:10.1200/JOP.2010.000015

42. The Lancet Neurology. Integrating palliative care into neurological practice. Editorial. Lancet Neurol (2017) 16:489. doi:10.1016/S1474-4422 (17)30176-X

43. Wallace EM, Tiernan E. Referral patterns of nonmalignant patients to an Irish specialist palliative medicine service: a retrospective review. Am J Hosp Palliat Care (2013) 30(4):399-402. doi:10.1177/1049909112453080

44. Yohannes AM. Palliative care provision for patients with chronic obstructive pulmonary disease. Health Qual Life Outcomes (2007) 5:17. doi:10.1186/1477-7525-5-17

Conflict of Interest Statement: The authors declare that the research was conducted in the absence of any commercial or financial relationships that could be construed as a potential conflict of interest.

Copyright $\odot 2018$ Anneser, Arenz and Borasio. This is an open-access article distributed under the terms of the Creative Commons Attribution License (CC BY). The use, distribution or reproduction in other forums is permitted, provided the original author(s) and the copyright owner are credited and that the original publication in this journal is cited, in accordance with accepted academic practice. No use, distribution or reproduction is permitted which does not comply with these terms. 